\title{
QUANDO DIFERENÇA E ACOLHIDA SE ENCONTRAM: IGREJA E MIGRAÇÕES
}

\author{
When difference and reception meet: \\ the church and migrations
}

\author{
Marileda Baggio*
}

\section{RESUMO}

A migração é tão antiga quanto a humanidade. Ela pode tomar rumos diversos no decorrer da história. Contudo será sempre um destacar-se das relações familiares, da terra natal, da cultura e da língua de origem e até do modo de viver a fé. É nessa migração dos povos que a Igreja se mobilizou. Com métodos pastorais diversos, ela sempre marcou presença no caminhar da humanidade. Avanços se fizeram notar no passar dos séculos. É depois do Vaticano II que a Igreja assume verdadeiramente seu rosto de Jesus Peregrino. Faz-se migrante com os migrantes. Hoje ela se faz presente nas várias faces da migração, trocando sua versão assistencialista, pela vivência da alteridade e da acolhida em meio ao povo de Deus migrante. É acolhendo o diferente que haverá o encontro com o próprio Jesus Cristo.

Palavras-chave: Igreja. Migrações. Alteridade. Acolhida.

\footnotetext{
* Religiosa da Congregação das Irmãs Missionárias de São Carlos Borromeo-Scalabrinianas, com bacharelado em Teologia na Escola superior de Teologia e Espiritualidade Franciscana (ESTEF) de Porto Alegre (RS). Realizou mestrado em Teologia Sistemática e em Espiritualidade na Pontifícia Universidade Gregoriana (PUG), Roma, onde também concluiu Doutorado em 2006. Atualmente é pesquisadora bolsista da CAPES (Coordenação de Aperfeiçoamento de Pessoal de Nível Superior)/MEC, pelo Programa Nacional de Pós-doutorado (PNPD), PNPD No 4176-38/2010, no projeto da Pontifícia Universidade Católica do Rio Grande do Sul (PUCRS), onde desenvolve pesquisa relacionada às: Novas linguagens em Teologia num mundo plural. É professora colaboradora no Programa de Pós-Graduação em Teologia.
}

\begin{tabular}{|l|l|l|l|l|l|}
\hline Teocomunicação & Porto Alegre & v. 44 & n. 2 & p. 261-280 & maio-ago. 2014 \\
\hline
\end{tabular}




\begin{abstract}
The migration is as old as humanity. It can take several directions throughout history. However it will always be a stand out of the family relationships, of the birthplace, of the culture and language and even the way of living the faith. It is in this migration of the peoples that the Church mobilized itself. Using several pastorals methods it has always been present in the walk of the humanity. Advances have been noted over the centuries. It is after the Vatican II that the Church takes its face of Jesus pilgrim. It becomes migrant with the migrants. Today it is present in many faces of the migration by exchanging their welfare version for the experience of the otherness and acceptance among the people of God migrant. It is by welcoming the different that there will be the encounter with Jesus Christ.
\end{abstract}

Keywords: Church. Migration. Otherness. Acceptance.

\title{
Introdução
}

O presente artigo fala de uma realidade pouco visualizada pela nossa sociedade, qual seja, a realidade migratória. Até mesmo a Igreja durante sua história deu pouca importância ao fenômeno migratório. Embora em seus anais conste certo envolvimento, ela poderia ter feito mais pelos povos em mobilidade, dada sua estrutura e relevância social e política.

Parte-se de uma pequena iluminação bíblica do Antigo Testamento (AT) e do Novo Testamento (NT), destacando passagens em que povos se acolhem mutuamente, chegando até Jesus Cristo, que não faz diferença de pessoas, acolhendo-as e amando-as sem distinção. Segue-se dando uma imagem da Igreja como aquela que acolhe à semelhança do próprio Cristo no decorrer da história da humanidade.

Destacam-se ainda as grandes migrações do século XIX e XX até os nossos dias em que elas tomam vulto devido à globalização, sobretudo a econômica, implicando um grande contingente de pessoas em mobilidade. Assim, vai se perceber que a Igreja passa de uma metodologia pastoral assistencialista e salvaguarda da fé católica, para uma prática da acolhida, da solidariedade, da compaixão e da alteridade. Não são poucos os documentos em que os últimos Papas salientam esta emblemática realidade. E não só escrevem como conclamam os católicos e todas as pessoas de boa vontade para que vivam a solidariedade e vejam na pessoa do migrante a própria pessoa de Jesus Cristo Peregrino. 


\section{Eles sempre se acolheram: migrações no AT}

A migração é um fenômeno tão antigo quanto a própria humanidade. São as primeiras viagens dos povos. No Antigo Testamento, há exemplos significativos. Nele se verifica que a primeira migração foi por ocasião da construção da Torre de Babel, quando Deus dispersa seus filhos por toda a terra ( $G n$ 11,8-9). Israel é um povo de imigrantes no território de Canaã. São obrigados a emigrar pela fome e pelas perseguições políticas.

Além destas, outras longas e sofridas histórias de migrações tais como o Exílio do fim do século VI a.C. e a diáspora na época helenística. Seguramente essas também pertencem aos grandes fenômenos migratórios da história de todos os povos. Abraão foi o Patriarca que mais andou. Com seu clã parte desde Ur dos Caldeus e chega a Manre na Palestina, atravessando o Egito. "De acampamento em acampamento, Abraão chegou ao Negheb" (Gn 12,8-9). Está em contínuo caminhar: chega e recomeça tudo novamente. Na idade avançada, deve partir e recomeçar novamente na terra que Deus lhe indica $(G n 12,1 ; 15,7)$. É o homem da promessa $(H b 11,8-9)$. Caminha para o desconhecido. É o verdadeiro Êxodo. Conduz a um não lugar, enquanto não lhe é absolutamente possível estabelecer-se em nenhum lugar. Está sempre caminhando, sempre na condição de estrangeiro. A terra é a promessa e não um lugar geograficamente estabelecido. Dessa promessa nasce a esperança absoluta em Deus. ${ }^{1}$ É como dizem seus filhos Isaac e Jacó: "Meu pai era um arameu errante" (Dt 26,5-6).

O Êxodo do Egito, como evento fundador da história do povo de Israel, e a travessia do deserto são de suma importância teológica. $\mathrm{O}$ Povo de Israel tem uma forte experiência de Deus. O Êxodo constituise em um caminho de libertação humana, política e social. Trata-se de uma peregrinação, onde eles têm a possibilidade de reorientar a própria vida no caminho do único Deus (Ex 2,23b-25); 3,7-8; 20, 2; Dt 6,21; $7,8 ; 26,7-9)$. São graças concedidas por Deus que é misericordioso e libertador. Ele mesmo indica o peregrinar (Ex 13,17-19). Ele vai à frente e ao lado de seu povo $(E x$ 13,21-22). E juntos percorrem o mesmo caminho. Deus os acompanha com suas teofanias, prodígios (Ex 25,10). Quando Deus coloca seu povo à prova, é para educá-lo na própria liberdade (Ex 32,1-10; Ex 15,25; 16,4).

1 CALDUCH-BENAGES, Nuria. Migrazioni nel Antico Testamento. In Grazziano Battistella (a cura di). Migrazioni. Dizionario socio-pastorale. Cinisello Balsamo. Edizioni San Paolo, 2010, p. 20. 
O Exílio nada mais é que uma migração forçada da pátria por motivos políticos. É uma passagem difícil na história do povo de Israel. Em toda a migração forçada, é muito fácil que se percam as raízes, os vínculos, as ligações afetivas. Não há tempo para uma migração pensada. A liberdade possibilita o planejamento sem o qual a superação das dificuldades iniciais é ainda mais árdua. A consequência pode ser uma crise de espiritualidade no Deus único. Contudo o Deus do peregrino, do migrante, do estrangeiro é o Deus da tenda. O Deus do rei, do poder é o Deus do templo. O Deus verdadeiro não está no templo, ele segue seu povo. É o Deus da Aliança. Ele não se dá por vencido e mantém suas promessas. A dureza do Exílio ensinou ao povo de Israel que o cumprimento das promessas e a esperança de um futuro melhor não dependem das dificuldades do caminho apresentadas pela história, mas dependem somente do plano de Deus.

A diáspora hebraica se desenvolveu de forma dramática, constituindo-se em um fenômeno migratório complexo, causado pelas duas deportações dos reis da Assíria e da Babilônia. Os que não quiseram retornar à mãe pátria permaneceram, contudo, fiéis à língua, cultura e tradições, como atesta o próprio Talmud. ${ }^{2}$

As narrativas de diásporas e de migrações forçadas narradas pela Bíblia, são frutos, sobretudo de disputas de reinos que causavam problemas sociais de grande monta. O exemplo mais evidente é a grande presença de estrangeiros desamparados, órfãos e viúvas (Dt 24,19-22). Desassistidos pelo poder político, eles se tornam os preferidos de Deus. Entre as várias categorias de estrangeiros, como o ghe $r$, termo exclusivamente referido a esta categoria, ${ }^{3}$ está o $z \bar{a} r$. Este não tinha nenhum reconhecimento na sociedade, era totalmente excluído e deveria ser mantido distante por não ser hebreu e por ser ameaça religiosa. A atitude era de total reserva. Um segundo de estrangeiro era o ghēr. Este também abandonava suas pátria, e por vários motivos encontrava acolhida entre os israelitas. É o caso de Abraão em Ebrom $(G n$ 23,4) e Moisés na terra de Madian (Ex 2, 22). O estrangeiro ghēr, geralmente estava a serviço de um patrão israelita e não raro contado entre os indigentes por natureza como as viúvas e os órfãos (Dt 24, 14-15). Os pobres poderiam gozar do direito de respigar $(L v 19,9.23 .32$;

2 CALdUCH-BENAGES,Nuria. Migrazioni nel Antico Testamento. In: Grazziano Battistella (a cura di). Migrazioni. Dizionario socio-pastorale, p. 23 e 24.

3 SPREAFICO, Ambrogio. Straniero/Forestiero. In: Grazziano Battistella (a cura di). Migrazioni Dizionario socio-pastorale, p. 975. 
Dt 24,19-22; Lv 19, 10; Dt 24, 21-22). "Quando um imigrante habitar com vocês no país, não o oprimam. $\mathrm{O}$ imigrante será para vocês um concidadão: você o amará como a si mesmo, porque vocês foram imigrantes na terra do Egito (Dt 24, 19-22). Eu sou Javé, o Deus de vocês ( $L v 19,33-34) .{ }^{4}$ Deus liberta, não quer povo escravo (Êx 20,2). "Quem sequestrar uma pessoa, quer a tenha vendido ou ainda a tenha em seu poder, será punido de morte" (Ex 21,16).

O povo migrante é o preferido do Deus na história. É o povo da tenda (Gn 18,1-2;Ex 18,7). A tenda é o sinal do caminhar com Deus, da busca, do encontro, da pobreza e da simplicidade. A revelação bíblica ajuda a reinterpretar pastoralmente o fenômeno migratório uma vez que as migrações não deixam de ser a história da humanidade e os próprios desígnios de Deus, de eventos históricos que lidos à luz da Palavra de Deus e da fé, são interpretados como a própria Palavra e mensagem de Deus. Deus continua a dizer: "Eu sou vosso Deus" ( $\hat{E} x$ 20,2) e, para o povo migrante Deus continua a ser presença e nos pede "para praticar o direito, amar a misericórdia, caminhar humildemente com o seu Deus" $(M q$ 6,8).

O próprio ministério de Jesus, com sua proposta libertadora, só é entendido à luz do testemunho judaico da ação de Deus na história. Foi Ele quem primeiro colocou-se ao lado dos povos ameaçados na sua dignidade, como foram as deportações e a escravidão. A ação dos profetas do Antigo Testamento também é fundamental para compreender a missão de Jesus. ${ }^{5}$

\section{Jesus Cristo: "o espírito do Senhor está sobre mim..."}

Jesus tinha consciência de seu ministério ( $L c 4,18-19)$. O ministério do Ungido é em primeiro lugar ter compaixão e misericórdia dos outros: mulheres, doentes, crianças, pobres, famintos (Mt 25,31-46). Sua missão era libertar, pois é para o amor e "para a liberdade que Cristo nos libertou" ( $G l 5,1)$. A exemplo dos patriarcas Jesus "planta sua tenda em meio a nós $\left(J_{o} 1,14\right)$. Jesus nasce entre os animais em uma estrebaria ( $L c$ 2,7); foge para o Egito como um exilado a exemplo do próprio Povo de Deus (Mt 2,3-23). Jesus não tem onde repousar a cabeça (Mt 8,20; Lc 9,58). Os evangelistas o recordam em terras estrangeiras

4 DANESI Giacomo; GAROFALO Salvatore. Migrazioni e accoglienza nella Sacra Scrittura. Edizione Messaggero. Padova, 1987, p. 169-174.

5 CNBB, Campanha da Fraternidade e tráfico humano, 2014, n. 129, p. 52. 
(Mc 7,24-37). É itinerante na sua missão. É estrangeiro, “de Nazaré pode sair coisa boa?" $\left(J_{o} 1,46\right)$. Vive como hóspede. Confia na hospitalidade de pessoas generosas, como na casa de Pedro em Cafarnaum, ou na casa de Levi, Zaqueu e Simão fariseu e de muitas mulheres como nos relata o livro de Atos dos Apóstolos. Assim ensina os discípulos: veio entre os seus, mas os seus não o receberam ( $\left.J_{o} 1,10-11\right)$. O evangelista reforça a ideia de que Jesus é incompreendido porque mundo e Deus se tornaram reciprocamente estrangeiros (cf. Jo 6,42; 7, 27-29; 8, 19; 9,29). Jesus realiza com perfeição o projeto de Deus para com a humanidade. É Ele, portanto, a medida de cada pessoa humana porque Ele é autêntico e seu projeto de vida foi plenamente fiel ao do Pai.

A revelação neotestamentária transmite uma mensagem original: ensina como amar o estrangeiro, porque o próprio Deus se revela no estrangeiro. Desse ponto de vista ele não é uma categoria sociológica, mas teológica. Deus ama a pessoa humana como o "outro". E a pessoa, sentindo-se amada por Deus, é capaz de amar o outro como irmã/irmão. Foi Deus que nos amou primeiro. É Ele o primeiro amor (cf. Ap 2,4). Essa é a verdadeira dimensão da acolhida na Bíblia. É uma urgência em qualquer contexto, como já disse Paulo, em acolherem-se uns aos outros da mesma forma que o próprio Jesus os acolheu (cf. $R m$ 15,7). Esta acolhida se traduz no aperfeiçoamento da prática da hospitalidade (Mt 25,31ss). Assim foi a prática do próprio Jesus, identificando-se com o estrangeiro, com o pobre, com as pessoas vulneráveis. ${ }^{6}$

Da mesma forma com que o Espírito do Senhor esteve sobre a missão de Jesus, esteve com a comunidade primitiva, fundada sobre a tradição apostólica. Seguiu a característica itinerante, peregrina, como era a prática dos apóstolos. A missionariedade fazia parte da continuação dos ensinamentos de Jesus. Tinha como elemento constitutivo a profissão de fé, o Batismo, a Eucaristia, a participação dos fiéis nas assembleias e no testemunho do Evangelho por todo o mundo (Cf. Mc 16,15). O mundo é a oportunidade do confronto entre as várias culturas, religiões, etnias. A comunidade apostólica é então interpelada a mudar continuamente sua ótica. Vê, sobretudo, que deve julgar o mundo conforme o projeto do Reino e os valores do Evangelho. A Igreja católica, florescente na época apostólica, indicava a universalidade da dimensão eclesial, do ser Igreja e a comunhão dos cristãos entre si. São sinais evidentes da universidade da Igreja desde sua origem.

6 BENTOGLIO, Gabriele. Nuovo Testamento. In Grazziano Battistella (a cura di). Migrazioni Dizionario socio-pastorale, p. 714-719. 


\section{Igreja e migrações sob a ação do Espírito (1860-1960)}

Podem-se quantificar os movimentos migratórios através da história e da tradição dos povos de forma escrita, oral, etc. É difícil, no entanto, quantificar a presença do Espírito do Senhor, manifestada através da ação da Igreja missionária na história da humanidade. Profetas sempre existiram. Eles agem de forma silenciosa, discreta, muitas vezes despercebida. O Espírito é sopro, vivifica. Nas migrações, a vida é manifestada através da coragem e da esperança em dias melhores.

Mesmo que o Espírito do Senhor aja na história, esta nunca deixou de apresentar seus tropeços que servem para avaliar os trajetos. Marcos históricos traçaram a vida da sociedade mundial. Entre elas destaca-se a Revolução Francesa, em 1789. Este acontecimento promoveu profundas transformações, sobretudo na Europa, com repercussões na economia, na vida política e nas culturas. Desde então, a Europa começou a passar por vários movimentos de transformação, entre eles a Revolução Industrial no final do século XVIII. Daí se disseminou e se solidificou por todo o Continente Europeu durante o século seguinte. A era da industrialização era irreversível. Em consequência disso, haveria a mudança no campo e na cidade.

A imigração se fazia necessária, por isso era apoiada pelos governos. Era necessário desocupar as terras para torná-las produtivas para a agricultura. Nas Américas havia terras que precisavam ser cultivadas. Necessitava-se de mãos humanas para produzir. A migração se encaixou bem nesta economia que despontava. Era uma válvula de escape. A lógica foi despopularizar para mecanizar as terras na Europa e não inchar as periferias das grandes cidades que ora tornavam-se industriais. Não havia infraestrutura que suportasse tamanha leva de migrantes do campo para as periferias das cidades. A "massa sobrante" era destinada à imigração. A industrialização selecionava as pessoas. As transformações atingiam a economia, sobretudo repercutindo na decisão de muito migrarem.

Nas cidades europeias, nascia uma nova classe social, o proletário, que pouco a pouco foi deixando de frequentar a Igreja, tornando-se cada vez mais laico. Nas colônias de imigrantes, por outro lado, sentia-se o abandono e a necessidade de cultivar a fé através dos sacramentos e da vivência eclesial. Sentiam também a ruptura com os tradicionais laços familiares e comunitários como consequência de um processo de transformação e crise das pessoas. Apesar da dureza, pois o destino de muitos foi encontrar uma terra inóspita, para elas se oportunizara o 
sonho da fortuna, ou da sobrevivência, fora da pátria. Particularmente a imigração italiana assumiu nos anos de 1880 grandes proporções de massa, com cerca de meio milhão de pessoas ao ano.

A imigração forçada estava relegada à miséria em seus países de destino. A sensação era de abandono por parte dos governos e também da Igreja. Os rebanhos sem pastores, paulatinamente vão sendo assistidos. É nesse contexto que surgem os profetas e que decidem acompanhá-los nos países de emigração. É o exemplo do padre italiano Vincenzo Pallotti que, bem antes das grandes imigrações nas Américas, foi pioneiro na assistência aos emigrantes, enviando em 1844 a Londres sacerdotes para assisti-los. Os Palotinos, sempre sensíveis ao problema das migrações, também enviaram a Nova York, ao Brooklyn e ao sul do Brasil padres para assistência aos migrantes, no ano de 1884. Estas ações mexeram também com a Igreja local. Em 1883-1884, em Baltimore nos Estados Unidos houve um concílio onde, a pedido da Santa Sé, se debateu a sensibilidade das igrejas de partida e de chegada dos migrantes. A preocupação de Baltimore era a inexistência de um plano de ação, sobretudo no que se referia ao respeito às culturas. Um caso típico de desrespeito à cultura ocorreu com os imigrantes italianos nos EUA, estabelecidos nas periferias das grandes cidades. Com seu jeito particular de devoção aos santos, de fazer procissões e de celebrar as festas, eram acusados de idolatria e paganismo, discriminados pelos católicos irlandeses, alemães, franceses. No Brasil, os imigrantes italianos estavam dispersos nas longínquas terras, sem assistência religiosa. A Propaganda Fidei solicita a ajuda dos bispos italianos mais sensíveis à problemática das migrações. Surge então o Bispo de Piacenza, Giovanni Battista Scalabrini, que no ano de 1887, funda uma Congregação religiosa masculina e, em 1895, a congregação feminina para assistência espiritual e social dos italianos emigrados nas Américas.

Outro grande nome do acompanhamento dos imigrantes italianos foi João Bosco que iniciou sua expansão missionária em 1875, endereçada à evangelização da Patagônia, na Argentina, expandindose depois para a capital Buenos Aires e para os pampas, com empenho religioso e educativo. ${ }^{7}$ A preocupação de João Bosco, bem como a do Bispo de Piacenza, João Battista Scalabrini, era a educação cristã

ROSOLI, Gianfausto. Insieme oltre le frontiere. Roma, Salvatore Sciascia Editore, 1996, p. 35 . 
das crianças e o isolamento das comunidades eclesiais a que estavam relegados os imigrantes. ${ }^{8}$

\section{A Igreja é mãe que acolhe}

A imagem de Igreja Mãe já fala por si. “A Igreja como Mãe deve sentir-se como igreja sem fronteiras, iIgreja familiar, atenta ao fenômeno crescente da mobilidade humana em seus diversos setores" (DAp n. 412).

Desde meados do século XIX, o empenho missionário por parte dos bispos e Congregações religiosas se tornava urgente. A situação a que estavam relegados milhões de imigrantes necessitava de vizinhança pastoral e solidariedade. Bem longe da era digital que aproxima as pessoas, a imigração significava perda das relações familiares e de amigos, da cultura nativa, da língua e, por vezes, também da fé. A imigração tinha a conotação de um constante "recomeçar". Todavia, embora de forma precária, as comunicações aconteciam. Serviam para sensibilizar e colocar-se em atitude de escuta. Assim fez Scalabrini, considerado por Pio IX o "Pai dos Migrantes", quando recebia relatos de seus compatriotas. Um deles, um colono emigrado no Brasil, relata que viviam como animais em meio à floresta, sem comunidade, sem missas e sem sacramentos.

Era indispensável um empenho missionário e, além disso, um empenho do episcopado, seja na Igreja de saída quanto na de chegada dos migrantes. É neste clima de compaixão por saber que seus compatriotas estão na miséria que Scalabrini escreve ao papa Leão XIII uma carta que a chama de Quam aerumnosa. ${ }^{9}$ Essa carta posteriormente foi apresentada aos bispos norte-americanos e se constituiu em um programa que tentava responder à especificidade de um apostolado difícil, que objetivava manter os filhos da Igreja no seu seio ou a reconquistá-los se estivessem fora dela. Nela o papa fala sobre a miséria e o abandono em que está relegada a massa de imigração:

Quão dolorosa e sofrida seja a condição dos que, cada ano, emigram, em massa da Itália para as regiões da América em busca de meios de subsistência [...]. É deplorável que tantos pobres cidadãos italianos coagidos pela pobreza a mudar de pátria muitas vezes sofrem angústias mais graves das quais quiseram fugir [...].

\footnotetext{
8 MOTTO, Francesco. Bosco (Don) Giovanni e la missione dei salesiani per i migranti. In Grazziano Battistella (a cura di). Migrazioni Dizionario socio-pastorale, p. 61.

9 Leão XIII, Quam aerumnosa (10.12.1888).
} 
Scalabrini também pensou na dificuldade de entrosar os vários grupos étnicos vindos da Europa, com os já existentes seja no Brasil como na América do Norte. Temia o enfraquecimento da fé e o sentimento cristão pela falta de acompanhamento através de sacerdotes da mesma origem dos migrantes. Geremia Bonomelli, bispo, também defendia a inserção da Igreja nos aspectos temporais, culturais e espirituais da sociedade contemporânea, especialmente entre os trabalhadores e os pobres. ${ }^{10} \mathrm{E}$, em 1900, fundava sua "Obra de assistência para os italianos emigrados na Europa".

Nesta época a Igreja solicitava aos bispos que adotassem medidas para a migração contemporânea. Os emigrantes precisavam ser instruídos e prevenidos sobre a realidade nos países de imigração. As principais preocupações da Santa Sé eram aqueles de uma astuta e ativíssima propaganda protestante e socialista. ${ }^{11}$

A Igreja Mãe que acolhe não pode contar com pessoas isoladas comprometidas com as causas migratórias e suas consequências sociais e eclesiais. A Igreja, com sua característica de universalidade, abre-se para o mundo e vê no mundo. Leão XIII, com a encíclica Rerum Novarum, emanada depois um século da Revolução Industrial, deu abertura rumo às coisas novas em âmbito universal. Sua preocupação maior era a "tutela da pessoa humana e da dignidade da classe trabalhadora". ${ }^{12}$ Dentro das mudanças da época, estava a migração à qual Leão XIII lembra que "ninguém, com efeito, quereria trocar por uma região estrangeira a sua pátria e a sua terra natal, se nesta encontrasse os meios de levar uma vida mais tolerável" (RN 65).

Esse compromisso de abertura universal da Igreja envolveu várias pessoas, com destaque para vários bispos entre eles os já citados Bonomelli e Scalabrini. Enquanto Bonomelli permanece no contexto europeu, Scalabrini, com o Memoriale per la Costituzione di uma Commissione Pontificia, pro Emigratis Catholicis (1905), pensou de maneira universal. Ele estava consciente dos contrastes de nacionalidades, sobretudo depois de suas duas viagens ao exterior: Estados Unidos, em 190; Brasil e Argentina, em 1905. Nesse mesmo ano, apresenta a Pio X o referido projeto. O memorial tinha por objetivo "prover a assistência pastoral dos migrantes de todas as nacionalidades, especialmente nas

\footnotetext{
${ }^{10}$ BENTOGLIO, Gabriele. Nuovo Testamento. In: Grazziano Battistella (a cura di). Migrazioni Dizionario socio-pastorale, p. 721

${ }^{11}$ ROSOLI, Gianfausto. Insieme oltre le frontiere, p. 50.

12 BAGGIO, Marileda. Entre dois mundos: A Igreja no pensar e no agir de Giovanni Battista Scalabrini. CSEM, Brasília, 2011, p. 105.
} 
Américas, com a finalidade de manter vivos nos corações, a fé católica e o sentimento cristão e reconduzir os que os perderam". ${ }^{13}$ Sugere que o clero seja possivelmente da mesma nacionalidade dos imigrantes ou, ao menos, que fale a mesma língua. ${ }^{14}$ Era importante a instituição de um organismo da cúria romana que coordenasse a pastoral e a assistência aos emigrantes católicos, favorecendo o recíproco acordo e clareando os frequentes inconvenientes de separação de alguns grupos e da marginalização no interior da Igreja de acolhida. ${ }^{15}$ Propôs uma organização de trabalho e de apostolado que deveria emanar da Santa Sé, junto a todo clero católico, de natureza universal e que abraçasse todas as nacionalidades. ${ }^{16}$ Scalabrini sublinha a função da religião no desenvolvimento histórico da nacionalidade e na conservação da fé, dos migrantes nas terras e imigração. ${ }^{17}$

No sentido de reforçar esta comissão, Pio X, em 1908, fundou as comissões diocesanas e paroquiais a favor dos emigrantes com a finalidade de oferecer apoio e formação aos que partiam. ${ }^{18}$ Em 1912, constituiu junto à Congregação Consistorial uma secção especial para os emigrantes católicos de rito latino com o Motu Próprio Cum omnes catholicos. O decreto Magni semper (1918), posterior ao Código de Direito Canônico, estabelecia o procedimento de autorização do clero para a assistência aos migrantes, sob a vigilância da Congregação Consistorial. Após a II Guerra Mundial, agravou-se a situação dos refugiados e dos migrantes. Pio XII com a Constituição Exsul família ${ }^{19}$ (1952), considerada a Magna Charta para a assistência espiritual dos migrantes, traça uma panorâmica histórica das intervenções da Igreja nesse campo e coordena as normas eclesiásticas sobre o tema.

${ }^{13}$ SEGANFREDO, Mafalda. Projeto sócio pastoral de João Batista Scalabrini (Pro Emigratis Catholicis). In: Profetismo e identidade apostólico-missionária da Irmã Scalabriniana. CSEM, Brasília, 2001, p. 71.

${ }^{14}$ ROSOLI, Gianfranco. Insieme, oltre le frontiere, p. 445.

${ }^{15}$ FRANCESCONI, Mario. Un progetto di Mons. Scalabrini per l'assistenza religiosa agli emigrati di tutte le nazionalità. In: Studi Migrazioni, n. 25-26, p. 185-203, 1972.

${ }^{16}$ SCALABRINI, Giovanni Battista. Memoriale per la costituzione di una commissione pontificia, Pro emigratis catholicis. In: TOMASI, Silvano; ROSOLI, Gianfranco (Ed.). Scalabrini e le migrazioni moderne, Roma, 1985, p. 230.

${ }^{17}$ SCALABRINI, Giovanni Battista. Memoriale sulla necessità di proteggere la nazionalità degli emigrati. In: TOMASI, Silvano; ROSOLI, Gianfranco (Ed.). Scalabrini e le migrazioni moderne, p. 61-69.

${ }_{18}$ NEGRINI, Angelo. La Santa Sede y el fenómeno de la Movilidad Humana. In: PeMo, v. 34, n. 88-89, p. 194-195, 2002.

${ }^{19}$ Embora venha a ser substituída pela Instrução De Pastorali Migratorum Cura, de 22 de agosto de 1969, ela permanece como um documento de referência. 
A família de Nazaré em exílio, Jesus, Maria e José, emigrantes no Egito e ali refugiados, fugindo da ira de um rei ímpio, são o modelo, o exemplo e o sustento de todos os emigrantes e peregrinos de cada idade e de cada país de todos os prófugos de qualquer condição que, perseguidos e necessitados, são obrigados a abandonar sua pátria, os parentes, os vizinhos, os amigos e a refugiar-se em terra estrangeira (n. 1).

Essa constituição confirma o direito natural de migrar, o destino universal dos bens da terra e a orientação para uma maior justiça na distribuição das riquezas do mundo. ${ }^{20}$ Depois de vinte anos dessa Constituição, foi necessário prever uma nova disciplina para a pastoral migratória, uma vez que nesta época o fenômeno migratório tinha se modificado.

Depois da prática centenária de uma pastoral estritamente ligada aos confins territoriais, a Exsul familia dava sinais de uma abertura antropológica por defender a cultura e a identidade religiosa dos migrantes. Introduziam-se, assim, elementos de pluralismo na assistência aos migrantes, contra a tendência a uma imediata assimilação característica da pastoral de muitos episcopados, onde havia pequenas comunidades de migrantes. Contudo, insiste-se que a responsabilidade primeira pela pastoral dos migrantes é do Bispo diocesano. Institui uma rede coordenada pelos organismos nacionais e diocesanos, seja nas igrejas de partida quanto de chegada dos migrantes, dando à emigração um sentido missiológico. A Igreja é a família dos Filhos de Deus que continuam a ser estrangeiros, migrantes e itinerantes, e se mostra incompleta e insuficiente à realização humana. ${ }^{21}$

\subsection{Paulo VI: "Especialistas em humanidade"}

A virada copernicana eclesial não havia sido concluída e Paulo VI já falava na ONU (1965) que a Igreja deve ser "técnica em humanidade". ${ }^{2}$ A realização do Concílio Vaticano II trouxe à tona aspectos novos para

${ }^{20}$ NEGRINI, Angelo. La Santa Sede y el fenómeno de la Movilidad Humana. In: PeMo, v. 34, n. 88-89, p. 195, 2002.

${ }^{21}$ BENTOGLIO, Gabriele. Nuovo Testament. In: Grazziano Battistella (a cura di). Migrazioni Dizionario socio-pastorale, p. 721

22 Paulo VI discurso na ONU, 4 de outubro de 1965, in <http://www.vatican.va/holy_father/ paul_vi/speeches/1965/documents/hf_p-vi_spe_19651004_united-nations_po.html >. Acesso em: 11 set. 2014. 
uma teologia da pastoral dos migrantes. Paulo VI, com o Motu Proprio Pastoralis Migratorum Cura (1969), aviava a revisão da Constituição Exsul família, concretizada com a instrução De Pastorali Migratorum Cura. Neste Motu Proprio, recorda a solicitude da Igreja para aqueles que foram obrigados a migrar longe de sua própria pátria. ${ }^{23}$

Ainda Paulo VI, com o Motu Proprio Apostolicae caritatis (1970), instituía a Pontificia Comissione, com sua autonomia operativa, com várias iniciativas de interesse das pastorais da mobilidade humana e do turismo. Essa comissão, com a publicação da Constituição Apostólica Pastor Bonus (1988), tornou-se o atual Pontificio Consiglio della Pastorale per i Migranti e Itineranti, de caráter autônomo, que tem por objetivo coordenar as Conferências episcopais e promover iniciativas em vista à sensibilização dos diferentes setores que compõem a pastoral da mobilidade humana. Segundo Paulo VI, na Encíclica Ecclesiam suam (1964), a Igreja faz-se palavra, faz-se mensagem, faz-se diálogo. Diálogo que se torna uma palavra-chave para o apostolado junto aos migrantes. A obra evangelizadora da Igreja é resposta a uma vocação do alto e ao mesmo tempo resposta a um mundo que, segundo a Evangelii nuntiandi, reclama evangelizadores que falem de um Deus que conheçam e que lhes seja familiar, como pudessem ver o próprio invisível (EN 14-16).

A Igreja é a intercessora dos povos pobres e "especialista" em humanidade ( $P P$ n. 1). Sua missão e profetismo tornam-se sempre mais importantes na medida em que a voz de seus filhos torna-se cada vez mais indefesa. A Igreja tem a tarefa de ser a voz dos que não têm voz. Segundo Paulo VI, o desenvolvimento dos povos, em modo particular dos que lutam para libertar-se da escravidão e da fome, da miséria, das doenças endêmicas, da ignorância, dos que buscam uma participação mais ativa para contribuir com a civilização, valorização das suas potencialidades humanas, é objeto de uma atenta observação por parte da Igreja ( $P P$ n. 1), e cabe a ela ser a acolhedora das novas situações migratórias e inserir-se nas suas dificuldades ( $P P$ n. 69). A Encíclica Populorium progressio ressalta que, para os povos terem pleno desenvolvimento, é necessário um humanismo total, aquele que não se fecha aos valores do Espírito. Para um desenvolvimento solidário da humanidade não se pode prescindir da fraternidade, da solidariedade, das relações, da

${ }^{23}$ De PAOLIS, Velazio. La cura dei migranti il Motu Proprio "Pastoralis Migratorum Cura" e l'Istruzione "De Pastorali Migratorum Cura". In: Studi Migrazione 53, CSER-Roma 1979, p. 341. 
caridade e da acolhida que, são as palavras sempre atuais da $P P$ n. 69. Não há, portanto, verdadeiro humanismo senão o aberto ao Absoluto $(P P$ n. 42). Crescer culturalmente e como pessoa humana, chamando isso de "homem integral", acrescenta a Pacem in terris n. 21.

\subsection{Somos todos irmãos: o Migrante na pauta do Vaticano II}

$\mathrm{O}$ pensamento social católico referente às migrações tem se afirmado sobre a solidariedade, baseado na Sagrada Família em fuga para o Egito. Nessa dinâmica, os cristãos devem ver nos refugiados e nos migrantes o próprio rosto de Cristo.

A relação da Igreja Católica com a migração até o Concílio Vaticano II caracterizava-se por ser estruturada, sacramental, assistencial e caritativa. Esse oportunizou a abertura ao diálogo inter-religioso e ecumênico e mudou seu linguajar em relação às migrações. $\mathrm{O}$ discurso apologético de defesa da unidade da Igreja, a defesa e preservação da fé católica, foram trocados pela atitude de defesa da vida humana, promoção da fraternidade, do diálogo e, sobretudo da acolhida da pessoa humana, como única, necessitada, criada à imagem e semelhança de Deus. A igualdade entre os seres humanos deve ser cada vez mais reconhecida, enfatiza a $G S$ n. 29. "Tudo o que temos dito sobre a dignidade da pessoa humana, sobre as comunidades dos homens e sobre o significado último da atividade humana, constitui o fundamento das relações entre a Igreja e o mundo e também a base de seu diálogo mútuo", fala a GS n. 40.

Os últimos anos, mostram que a migração tomou formas gigantescas e que não se pode tratar apenas de migração senão que de uma verdadeira mobilidade humana sem limites. Hoje é mais de um bilhão de pessoas que estão constantemente em movimento. ${ }^{24}$

Essa mudança influenciou também a sociedade que passou de uma visão de migração como um mal necessário, para um potencial a enriquecimento e intercâmbio entre as culturas: "A missão da Igreja implica a defesa e a promoção da dignidade e dos direitos fundamentais da pessoa humana"; 25 "a descoberta nos rostos sofredores dos pobres o rosto do Senhor (Mt 25,31-46) é algo que desafia todos os cristãos a uma profunda conversão pessoal e eclesial aponta a $S D$ n. 178. Chama-se

\footnotetext{
${ }^{24}$ Mundo tem quase um bilhão de migrantes. In: <http://www.pnud.org.br>. Acesso em: 22 set. 2014, p. 1-2.

${ }^{25}$ Sínodo dos Bispos (1971). A justiça no mundo. <http://www.vatican.va/roman_curia/ synod/>. Acesso em: 22 set. 2014.
} 
a atenção para uma "fraternidade humana universal. Somos todos irmãos e devemos ter consciência disto". ${ }^{26}$ Cada pessoa humana deveria ter a liberdade de decidir sobre seu próprio futuro, destaca a GS n. 17. A Octogesima adveniens n. 8, fala dos "novos problemas sociais" decorrentes deste contexto industrial que é o urbanismo. Com o abandono das zonas agrícolas acontecerá o inevitável êxodo e o consequente inchaço das periferias. ${ }^{27}$ Tendo clara a irreversibilidade dos sinais dos tempos, preocupa-se com as migrações: o consumismo, "escravo dos objetos que produz" e os vários tipos de discriminações: raça, origem, cor, cultura, sexo e religião. Contudo, ressalta o João Paulo II, é direito do ser humano migrar e é dever, sobretudo, dos cristãos trabalharem para instaurar a fraternidade universal, base indispensável da justiça autêntica e da condição de uma paz duradoura (n. 17. Advinda dos direitos humanos, pela força do Evangelho, acompanhará o dinamismo dos novos tempos, diz a GS n. 41.

A função pastoral dos bispos na Igreja, repete a Christus dominus n. 18, é para que tenham solicitude com certos grupos de fieis devido à condição de vida: numerosos migrantes, os expulsos e refugiados, os marinheiros e os aviadores, os nômades e outros semelhantes. É uma renovação conciliar considerada seja pela sua doutrina eclesiológica seja pela sua dimensão missionária. ${ }^{28}$

A desigualdade entre os países e o direito de migrar de toda pessoa humana foi contemplado na Gaudium et spes n. 65. A migração também ajuda a superar as desigualdades, bem como pode responder às esperanças das pessoas refugiadas e das famílias migrantes. Na maneira da Igreja entender a liberdade de migrar de cada pessoa, está a prática da sua universalidade, diz $G S$ n. 84. Nisso consiste a verdadeira fraternidade entre cristãos e não cristãos, onde haja solidariedade, respeito e amor para com toda a família humana, ressalta a $G S$ n. 3. Da exigência de promover a identidade integral da pessoa humana nasce a proposição

\footnotetext{
${ }^{26}$ FONDAZIONE MIGRANTES DELLA CONFERENZA EPISCOPALE ITALIANA. Enchiridium della Chiesa per le Migrazioni. Documento magisteriali Ed ecumenici sulla pastorale della mobilità umana (1887-2000). Bologna, Centro editoriale dehoniano, 2001, n. 601-602.

${ }_{27}$ Paulo VI falava de "megalópoles" na Octagesima adveniens n. 8: "Este êxodo rural permanente, o crescimento industrial, o aumento demográfico contínuo e a atração dos centros urbanos determinam concentrações de população cuja amplitude se torna difícil de imaginar, dado que se começa já a falar de "megalópoles". Mundo tem quase 1 bilhão de migrantes em: <http://www.fetecsp.org.br/index2>. Acesso em: 22 set. 2014.

${ }^{28}$ DE PAOLIS, Velasio. Chiesa e Migrazioni, Quaderni SIMI-2. Roma, 62.
} 
dos grandes valores que edificam uma convivência ordenada e fecunda. Verdade, justiça, amor e liberdade são as palavras fortes da Pace in terris n. 44, sabendo que somente "a libertação das injustiças promove a liberdade e a dignidade humana". ${ }^{29}$

\section{As novas categorias da mobilidade humana: o tráfico humano, os refugiados e deslocados à força}

O tráfico de pessoas é um tema tão antigo quanto a existência humana. É o caso de José do Egito ( Gn 37,13.28; II Reis 5,2). Por séculos a Igreja foi conivente com o tráfico humano. Beneficiava-se com ele. Afinal ela participava do mundo burguês para o qual era indispensável a servidão. Scalabrini, ainda na segunda metade do século XIX, chamava a isso de "comerciantes de carne humana".

$\mathrm{Na}$ era da globalização, ele pode ser perfeitamente camuflado. No comando das organizações criminosas, torna-se um crescente business. No centro do interesse pelo tráfico de pessoas, está um deslumbrante jogo econômico. O pivô é o mercado e as exigências cruéis da globalização mundial. Essa filosofia econômica se contradiz ao mandato de Deus que criou a pessoa humana para ser livre, amar e ter vida em abundância. Portanto, escravizar alguém é ir contra a dinâmica do próprio Criador, ressaltou a $G S$ n. 27. A globalização reifica as pessoas, empobrecendoas, seja econômica, humana e ou espiritualmente. Empobrecidas são presa fácil para serem escravizadas e traficadas. Enquanto "o luxo pulula junto à miséria" nas palavras da GS n. 63, mantendo o abismo entre ricos e pobres, haverá exploradores fazendo da própria pessoa humana um comércio rentável.

Jesus faz presente a vida plena, diante das estruturas de morte: $\mathrm{Eu}$ vim para dar vida aos homens e para que a tenham em plenitude" ( $J_{O}$ 10,10). "Por isso, cura os enfermos, expulsa os demônios e compromete os discípulos na promoção da dignidade humana e de relacionamentos sociais fundados na justiça" (Documento de Aparecida n. 112).

É na voz profética do Concílio Vaticano II que o tema do tráfico volta a ser uma das preocupações da Igreja.

A escravidão, a prostituição, a venda de mulheres e crianças e as condições de trabalho degradantes onde as pessoas são tratadas

${ }^{29}$ PONTIFÍCIO CONSELHO JUSTIÇA E PAZ. Compêndio da Doutrina Social da Igreja. São Paulo, Paulinas, 2005, n. 137. 
como instrumento de lucro em vez de pessoas livres e responsáveis, são infâmias que envenenam a sociedade e constituem uma suprema desonra ao Criador (GS n. 27).

A partir de 1978, João Paulo II e Bento XVI têm feito declarações anuais no dia Mundial dos Migrantes e Refugiados, estabelecida desde agosto de $1958 .{ }^{30} \mathrm{Em}$ nível de Conferências episcopais, a que merece mais destaques é a declaração de 2003 feita conjuntamente pelos bispos dos EUA e México, na qual os mesmos se comprometem em lutar para erradicar a pobreza e consequentemente diminuir a migração e o tráfico de pessoas. ${ }^{31}$

Frente aos novos sinais dos tempos, a Igreja vai se questionando e questionando, enquanto envolve todas as pessoas de boa vontade. Uma das palavras fortes que aparece constantemente nas palavras das autoridades eclesiais nas últimas décadas é o posicionamento de cada pessoa humana diante da realidade circundante. Como ficar indiferentes [...] frente ao vilipêndio dos direitos humanos fundamentais de tantas pessoas, especialmente das crianças é a provocação do Novo Millenium Ineunte n. 50-51.

A Igreja católica há anos, em diálogo com outras ciências, está reforçando o conceito de dignidade humana. Esta deriva do Deus da vida, pois a pessoa humana é criada à imagem e semelhança de Deus, reforça a Caritas in veritate, n. 45 . No dado pastoral, ela tem-se preocupado em ser presença em meio às migrações. A Instrução Pastoral Erga migrantes caritas Christi tem como objetivo servir de ajuda para práticas pastorais e guia para a interpretação dos sinais dos tempos. ${ }^{32}$ Mas é com o Papa Francisco que é possível identificar as palavras que sensibilizam a todos os povos. Na Evangelii Gaudium, percebe-se a alegria com que o papa se dirige às pessoas às quais já não têm mais motivos para ter alegrias. Trata-se de uma profunda serenidade de espírito e de um conhecimento e experiência pessoal das causas de tanto sofrimento por que passam

${ }^{30}$ SABBARESE, Luigi. Pontificio Consiglio della Pastorale per i Migranti e Itineranti. In: Grazziano Battistella (a cura di). Migrazioni Dizionario socio-pastorale, p. 855.

${ }^{31}$ Bispos dos Estados Unidos, México e América Central combaterão as causas da migração infantil. Disponível em: $<$ http://www.ihu.unisinos.br/noticias/533249-bispos-dos-estadosunidos-mexico-e-america-central-combaterao-as-causas-da-migracao-infantil $>$. Acesso em: 22 set. 2014.

32 PONTIFÍCIO CONSELHO DA PASTORAL PARA OS MIGRANTES E OS ITINERANTES. Erga migrantes caritas Christi, (Instrução), Città del Vaticano 2004. OU São Paulo, Paulinas, 2004. 
os povos e convida a "tomar cuidado da fragilidade humana" (n. 210). Revela sua preocupação a viva voz no discurso feito em Lampeduza a três meses de sua posse como chefe da Igreja Católica. Ele inquieta a todos com a pergunta, ferindo-se ao episódio bíblico $(G n 4,9)$ : “Onde está teu irmão"? Não ouvir o grito é fechar-se à escuta, à acolhida, à solidariedade, levando inevitavelmente à "globalização da indiferença" à qual "nos tirou a capacidade de chorar", ${ }^{33}$ diz o papa. Ainda papa Francisco, no Documento "Acolher Cristo nos refugiados e nas pessoas deslocadas à força", do ano 2013, afirma que "o amor se eleva acima de quaisquer limites ou distinções". É motivado pela caridade de Cristo. Cristo é acolhido na pessoa do preso, do peregrino, do faminto, do sedento (cf. $M t$ 25,35-36). A "Igreja oferece seu amor e sua assistência a todas as pessoas deslocadas à força, sem qualquer distinção de religião ou de proveniência, respeitando em cada uma delas a dignidade inalienável da pessoa humana, criada à imagem e semelhança de Deus". ${ }^{34}$ O Documento de Aparecida coloca os migrantes e refugiados entre os "rostos sofredores dos pobres" (n. 393.402) da população da América Latina e Caribe. Por diversas vezes fala da contribuição cultural das migrações e do respeito às diferenças culturais e religiosas das diversas nacionalidades dos povos em movimento (n. 56 e 59). Elas precisam ser acolhidas e respeitadas porque uma só é a família humana (n. 60).

\section{Conclusão}

O texto percorreu um caminho de alguns séculos e mostrou a ação da Igreja Católica no que se refere à abertura de seu pensamento e ações em relação às migrações. Até a metade do século XX, a preocupação da Igreja Católica era de não perder fieis para outras Igrejas, sobretudo a Luterana. Por isso enviava sacerdotes que na prática conservavam a mesma forma de viver a fé do lugar de imigração. Esta metodologia pastoral foi a prática de muitos anos com as comunidades de migrantes europeus.

Em meados do século XX, depois de um período de estagnação, a Igreja começa a fazer leitura teológica do fenômeno migratório, porém de forma pragmática e fragmentária. Depois da interrupção da guerra

\footnotetext{
${ }^{33}$ CNBB. Campanha da Fraternidade e tráfico humano, 2014, p. 104.

${ }^{34}$ PONTIFÍCIO CONSELHO PARAA PASTORAL DOS MIGRANTES E ITINERANTES; PONTIFÍCIO CONSELHO COR UNUM, Cidade do Vaticano 2013, Introdução.
} 
dos anos 1915-1918, as migrações tomam vulto. ${ }^{35}$ Com a Exsul familia, a Magna Charta das migrações na segunda metade do século XX, se dá início a uma nova fase na compreensão da presença eclesial junto aos migrantes. Ela vem em uma época de turbulências, sobretudo pelos refugiados da Segunda Guerra Mundial. A Igreja muda sua ótica. Em vez de colocar a responsabilidade da pastoral migratória somente nas mãos dos bispos e do clero, conclama a cada pessoa de boa vontade para se comprometerem com a causa. Mostra a face de Jesus Peregrino e, em vez de pensar somente no "fazer" pastoral, fala da riqueza da diversidade cultural ( $D A p \mathrm{n}$. 56), que desencadeia na acolhida $D A p \mathrm{n}$. 402, na alteridade e amor, dizendo que "é uma força extraordinária, que impele as pessoas a comprometerem-se, com coragem e generosidade, no campo da justiça e da paz", segundo a Caritas in veritate, n. 5. Este modo de ver e pensar a pessoa do migrante mostra uma Igreja comprometida com todos os povos. Trata-se "de assumir profeticamente esta pastoral específica [...]" DAp n. 412 e promover assim uma "cidadania universal na qual não haja distinção de pessoas", diz $D A p$ n. 414. Na ausência destes valores, haverá a "globalização da indiferença", parafraseando as palavras de Papa Francisco. Ele insiste para que cada cristão se sensibilize com esta realidade, sobretudo das pessoas forçadas a migrar e o tráfico de seres humanos. O outro não é um estranho, mas é irmão. Somente na dinâmica de acolher o diferente é que será possível viver como uma grande família humana. Até que isso não se concretize ...

Quando você perceber que, para produzir, precisa obter a autorização de quem não produz nada; quando comprovar que o dinheiro flui para quem negocia não com bens, mas com favores; quando perceber que muitos ficam ricos pelo suborno e por influência, mais que pelo trabalho, e que as leis não nos protegem deles, mas, pelo contrário, são eles que estão protegidos de você; quando perceber que a corrupção é recompensada, e a honestidade se converte em autossacrifício; então poderá afirmar, sem temor de errar, que sua sociedade está condenada. ${ }^{36}$

${ }^{35}$ DE PAOLIS, Velasio. Chiesa e Migrazioni, Quaderni SIMI-2, p. 214-215.

${ }^{36}$ Frase da filósofa russo-americana Ayn Rand, judia, fugitiva da Revolução Russa, que chegou aos EUA na metade da década de 1920, mostrando uma visão com conhecimento de causa. Pensador In: <http://pensador.uol.com.br/frase/ODQ0Mjc4/>. Acesso em: 08 ago. 2014. 
É em meio a essa massa da sociedade condenada que a Igreja torna-se sensível à realidade da migração. Embora seja um trabalho quase invisível aos olhos do mundo, a Igreja tem se preocupado com a realidade das migrações mundiais. E não só, mas tem sido uma voz que clama no deserto da indiferença e solicita a ajuda e o comprometimento de todos e de todas para que cada migrante seja acolhido, da mesma forma que o próprio Cristo acolhe a cada um/uma de seus/suas filhas. "A própria vocação, a própria liberdade e a própria originalidade são dons de Deus para a plenitude e o serviço ao mundo", (DAp n. 111).

\section{Referências}

BAGGIO, Marileda. Entre dois mundos: a Igreja no pensar e no agir de Giovanni Battista Scalabrini. Brasília: CSEM, 2011.

CALDUCH-BENAGES, Nuria. Migrazioni nel Antico Testamento. In: Grazziano Battistella (a cura di). Migrazioni. Dizionario socio-pastorale. Cinisello Balsamo. Edizioni San Paolo, 2010.

DE PAOLIS, Velasio. Chiesa e Migrazioni, Quaderni SIMI-2. Roma: Urbaniana University Press, 2005.

NEGRINI, Angelo. La Santa Sede y el fenómeno de la Movilidad Humana. In: PeMo, v. 34, n. 88-89, 2002.

PONTIFICIO CONSELHO DA PASTORAL PARA OS MIGRANTES E OS ITINERANTES COR UNUM, Cidade do Vaticano, 2013. Introdução.

PONTIFÍCIO CONSELHO DA PASTORAL PARA OS MIGRANTES E OS ITINERANTES. Erga migrantes caritas Christi (Instrução). Città del Vaticano, 2004.

ROSOLI Gianfausto. Insieme oltre le frontiere. Roma: Salvatore Sciascia Editore, 1996.

SEGANFREDO, Mafalda. Projeto sóciopastoral de João Batista Scalabrini (Pro Emigratis Catholicis). In: Profetismo e identidade apostólico-missionária da Irmã Scalabriniana. Brasília: CSEM, 2001. p. 71.

SCALABRINI, Giovanni Battista. Memoriale per la costituzione di una commissione pontificia: Pro emigratis catholicis. In: TOMASI, Silvano; ROSOLI, Gianfranco (Ed.). Scalabrini e le migrazioni moderne. Roma, 1985.

Recebido: 10/09/2014

Avaliado: 05/10/2014 